\title{
Autosomal dominant mendelian susceptibility to mycobacterial diseases due to partial IFNgammaR2 deficiency
}

INSERM

\section{Source}

INSERM. (1999). Orphanet: an online rare disease and orphan drug data base. Autosomal dominant mendelian susceptibility to mycobacterial diseases due to partial IFNgammaR2 deficiency. ORPHA:319589

Autosomal dominant (AD) mendelian susceptibility to mycobacterial diseases (MSMD) due to partial interferon gamma receptor 2 (IFN-gammaR2) deficiency is a genetic variant of MSMD (see this term) characterized by a partial deficiency in IFN-gammaR2, leading to impaired response to IFN-gamma and, consequently, to recurrent, moderately severe infections with bacillus Calmette-Guérin (BCG) and other environmental mycobacteria (EM). 